\title{
Strength and Conditioning Practices in ROWING
}

\author{
Thomas I. Gee, ${ }^{1}$ Peter D. Olsen, ${ }^{2}$ Nicolas J. Berger, ${ }^{3}$ Jim Golby, ${ }^{3}$ and Kevin G. Thompson ${ }^{1}$ \\ ${ }^{1}$ School of Life Sciences, Northumbria University, Newcastle, United Kingdom; ${ }^{2}$ Bridging Programs, University of Canterbury, \\ Christchurch, New Zealand; and ${ }^{3}$ School of Social Sciences $\mathscr{\sigma}^{\circ}$ Law, Teesside University, Middlesbrough, United Kingdom
}

\begin{abstract}
Gee, TI, Olsen, PD, Berger, NJ, Golby, J, and Thompson, KG. Strength and conditioning practices in rowing. $J$ Strength Cond Res 25(3): 668-682, 2011-There is limited published research on the practices of strength and conditioning $(\mathrm{S} \& \mathrm{C})$ coaches in Great Britain. Information about training program design would be useful in developing models of good practice and ecologically valid intervention studies. The aim of this research was to quantify the training practices of coaches responsible for the S\&C of rowing athletes. A questionnaire was developed that consisted of 6 sections: (a) personal details, (b) physical testing, (c) strength and power development, (d) flexibility development, (e) unique aspects of the program, and $(f)$ any further relevant comments regarding the athletes prescribed training program. Twenty-two rowing and $10 \mathrm{~S} \& \mathrm{C}$ coaches with an average of $10.5 \pm 7.2$ years' experience agreed to complete the questionnaire. Approximately, $34 \%$ coached rowers of Olympic standard, 34\% coached national standard, $3 \%$ coached regional standard, $19 \%$ coached club standard, and $10 \%$ coached university standard rowers. All coaches agreed that strength training enhanced rowing performance and the majority (74\%) indicated that athletes' strength trained 2-3 times a week. Almost all coaches (94\%) reported their rowers performed strength training, with $81 \%$ using Olympic lifting, and $91 \%$ employing a periodized training model. The clean $(63 \%)$ and squat $(27 \%)$ were rated the most important prescribed exercises. Approximately $50 \%$ of coaches used plyometrics such as depth jumps, box drills, and standing jumps. Ninety-four percent indicated they conducted physical testing on their rowers, typically assessing cardiovascular endurance (80\%), muscular power $(70 \%)$, muscular strength $(70 \%)$, and anaerobic capacity $(57 \%)$. This research represents the only published survey to date on the S\&C practices in rowing within Great Britain.
\end{abstract}

KEY WoRDs questionnaire, Great Britain, program design, testing, training, coaching

Address correspondence to Thomas I. Gee, thomas.gee@northumbriaac.uk.
25(3)/668-682
Joumal of Strength and Conditioning Research
(c) 2011 National Strength and Conditioning Association

668

\section{INTRODUCTION}

$\mathrm{R}$ owing is an Olympic sport that is popular worldwide and is considered one of the most demanding endurance sports (41). A typical rowing competition takes place over $2,000-\mathrm{m}$ rowing course and lasts 5.5-7.0 minutes (27). The dominant energy contribution in race rowing is from aerobic metabolism (31); however, anaerobic qualities such as muscular strength and power are also seen as important predictive factors in terms of the overall performance (7). Research has identified rowing specific strength and power to correlate well to 2,000-m ergometer performance. For example, Riechman et al. (39) found that $76 \%$ of the variation in 2,000-m rowing ergometer performance time was predicted by peak power in a 30 -second rowing Wingate test, whereas Secher (42) observed that maximal isometric rowing strength is significantly higher in international rowers than in both national and club rowers. In a study by Ingham et al. (23), international rowers performed 5 maximal rowing strokes. Maximal power and force produced during the 5 strokes were highly correlated with 2,000-m ergometer performance $(r=0.95)$. Rowing performance has also been found to be related to lower body strength and power. Battista et al. (1) reported that varsity rowers possessed higher vertical jumps than did novice rowers $(\sim 3 \mathrm{~cm})$. Russell et al. (41) have found maximal isokinetic knee extension at $1.05 \mathrm{rad} \cdot \mathrm{s}^{-1}$ to be significantly correlated $(r=-0.40)$ with 2,000 -m ergometer time and Yoshiga and Higuchi (57) found 2,000-m ergometer performance to significantly correlate $(r=0.62)$ with bilateral leg extension power in a study of 332 young oarsmen. These findings suggest that strength and power are essential physical components in rowing. Indeed the limiting factors to optimal performance in rowing have been identified as maximum strength, starting power, and muscular endurance for medium $(2,000 \mathrm{~m})$ to long distances $(6,000 \mathrm{~m})(46)$. It has been shown that rowing performance is highly correlated with maximal strength and power; therefore, it would seem appropriate that rowers should concentrate on developing these qualities $(1,23,39,41,42,54)$. Maximal strength and power have been shown to be optimally developed by training with heavy loads and low repetitions per set of an exercise (4,34). Indeed, McNeely et al. (30) recommend a resistance training program that focuses on the development 
of maximum strength, with low repetitions and loading between 85 and $95 \%$ of 1 repetition maximum (1RM) being the most effective for improving rowing performance. Electromyography (EMG) analysis suggests that the muscle groups that are used during rowing are active in combination (56). Therefore, it is recommended that rowers perform strength training exercises that require the upper and lower body to work together in a coordinated manner, leading to whole-body strengthening (40). The Olympic lifts, the squat, and the deadlift are whole-body exercises requiring coordinated actions of many muscle groups for their successful performance $(17,20,33)$, which is why these exercises have been highlighted as appropriate for rowers $(24,30)$. Ebben et al. (16) found that an 8-week resistance training program based around the aforementioned exercises led to improvements in performance time, total power, and power per stroke during a 2,000-m rowing ergometer test in both novice and varsity female university rowers. Despite these findings, few articles have described or made recommendations for strength and conditioning (S\&C) practices in rowing. Indeed only 2 guides for S\&C prescription and assessment of rowers have been published. A guide for strength training prescription for the preparatory training phase in collegiate female rowers has been published (24). This guide gave recommendations for anatomical adaptation, maximum strength and power training, fitness testing, injury prevention, and flexibility development. The 'maximum strength' training phase described in this plan featured 2 sessions a week, and generally 3 sets of 8 repetitions were prescribed per exercise. This phase involved mainly strength-based exercises such as squats, bench press, low cable row, step-ups, bent over row, and Romanian deadlift. However, power-based exercises such as the hang clean (on day 1) and high pull (on day 2) were also included. A 'power' training phase was also described. This phase featured 3 workouts a week during which more power-based exercises were prescribed including the hang clean, dumbbell push jerk, power shrugs, step up with jump, vertical jumps with a weighted vest and various explosive medicine ball exercises. Sets and reps on these power exercises generally ranged between 3-5 sets and 3-5 repetitions. Some strengthbased exercises were also included within this phase and generally performed for 2-3 sets of 8 repetitions. McNeely et al. (30) have published a report documenting recommended strength and power tests and performance goals for competitive rowers. This report recommended 1RM testing on the squat, bench pull, and deadlift for assessment of maximum strength and a 30-second 'modified Wingate test' on the rowing ergometer to assess anaerobic power. The authors also list strength to body weight standards for the squat, bench pull, and deadlift and power output standards for the 30-second rowing sprint test that should be achieved across differing levels of rower. Currently, these articles by Ivey et al. (24) and McNeely et al. (30) are the only published research that has given clear guidelines for strength training prescription for rowing. Clearly, there is a need for a greater understanding of $\mathrm{S} \& \mathrm{C}$ practices in rowing.

To date, there have been a number of studies that have focused on the S\&C practices of S\&C coaches in North America (12-15,44,48). However, to the author's knowledge, there is no research addressing $\mathrm{S} \& \mathrm{C}$ prescription within rowing or indeed any continuous endurance sport. Information related to common trends in exercise prescription for rowers could act as a useful reference source when designing training programs and developing ecologically valid intervention studies. The aim of this study was to survey a variety of training practices of coaches responsible for the $\mathrm{S} \& \mathrm{C}$ of rowers.

\section{Methods}

\section{Experimental Approach to the Problem}

The survey titled 'Strength and conditioning questionnaire' was adapted from research by Ebben and Blackard (13). The adapted questionnaire was pilot tested with an advisory group of $6 \mathrm{~S} \& \mathrm{C}$ coaches and exercise physiologists. The survey contained 6 sections: personal details, physical testing, strength and power development, flexibility development, unique aspects of the program, and any further relevant comments regarding the athlete's prescribed training program. The survey was distributed to rowing coaches and S\&C coaches who worked with rowers throughout Great Britain. Great Britain is presently one of the most successful rowing nations in the world. In the 2008 Olympics in Beijing and the 2004 Olympics in Athens, Great Britain finished first and third, respectively, in the rowing medal table. With the considerable global success of British rowers, we envisaged that the data obtained from this survey on S\&C practices would provide a useful reference to be used worldwide by those involved in the preparation of rowers.

\section{Subjects}

Before the initiation of data collection ethical approval was granted by Teesside University. Mailed surveys were sent with a self-addressed, stamped envelope, and an introductory letter describing the project was included with all mailed questionnaires. A number of coaches were also approached face to face at their place of work and rowing competitions. Data were collected between May 2007 and May 2008.

\section{Statistical Analyses}

The survey contained fixed-response and open-ended questions. Answers to open-ended questions were content analyzed according to methods described by Patton (36) that have been previously used in other surveys of professional sports $\mathrm{S} \& \mathrm{C}$ practices $(13-15,44)$. Investigators were trained and experienced with qualitative methods of sports science research and content analysis. For data analysis, each investigator generated raw result data and higher-order themes via independent, inductive content analysis and compared independently generated themes until agreement was reached at each level of analysis. When higher-order 
themes were developed, deductive analysis was used to confirm that all raw data themes were represented.

\section{Results}

\section{Personal Details}

Thirty-two (28 male, 4 female) of 54 (59.3\%) coaches responded to the questionnaire. Twenty-two of the participants were rowing coaches, and the other 10 were S\&C coaches. Mean age of the participants was $31.7 \pm 5.8$ years. Mean coaching experience was $10.5 \pm 7.2$ years. Twenty-five coaches reported having fellow coaching staff. Examples of fellow staff given by respondents were "Sports science support team," "Work within a coaching team of four, shared responsibilities for coaching university group," or with, "World class start colleagues (coaches of national youth-age rowers)" or as, "Part of a coaching team of 12 coaches for Olympic squad backed up two chief coaches" (texts in double quotes are direct quotations taken from the completed questionnaires). Table 1 provides a breakdown of the rowing coaches in terms of the highest level of athlete they had coached.

\section{Formal Education}

Eighty-one percent of respondents held a bachelors degree, and $34 \%$ held a masters degree. Of those who held a bachelors or a masters degree, 54 and $82 \%$ were in an exercise science or related field, respectively. One respondent held a postgraduate certificate in education, whereas 2 held Ph.D.s.

\section{Certification}

Rowing Coaches. The most prevalent certifications were those offered by the Amateur Rowing Association of Great Britain $(n=6)$. Three coaches possessed a British Amateur Weightlifters Association (BAWLA) qualification. Other qualifications possessed included: "United Kingdom Coaching Certificate level 3 rowing coaching," "United Kingdom Coaching Certificate level 2 strength and conditioning," "Australian rowing level II," and a "Diploma in sports massage."

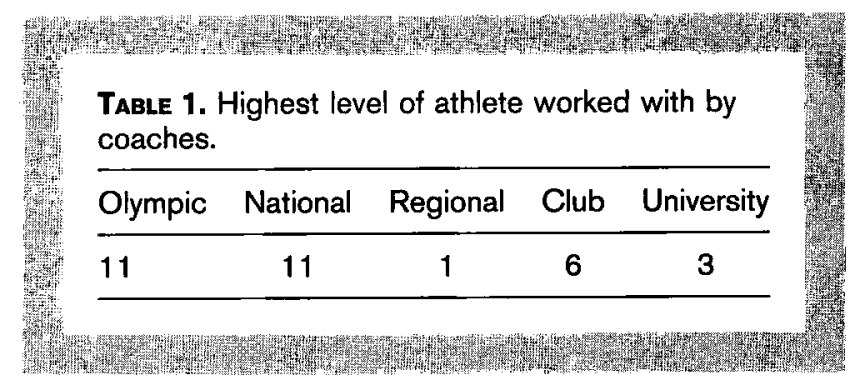

and the "USA Weightlifting Award," "YMCA Fitness Instructor Award."

\section{Physical Testing}

Thirty respondents indicated they conducted physical testing on rowers. Coaches were asked, when testing was performed (Figure 1), what aspects of fitness are tested (Figure 2), and what specific tests are used. Coaches reported testing an average of between 4 and 5 aspects of fitness. Coaches reported testing cardiovascular endurance using the following: "ergometer tests," "5 km, 30 minutes, $16 \mathrm{~km}$ or rowing ergometer," "step test," "18-km ergometer," "1-hour test." Muscular strength was assessed with either the: "1RM squat, deadlift, bench pull," "concept II dynamometer (world class start testing protocol)," and "1RM squat, push-pull, and deadlift," Muscular power was determined using "vertical jump and max Olympic lift," "max power at $100^{\circ} \cdot \mathrm{s}^{-1}$," and " $250-\mathrm{m}$ ergometer," "ballistic measurement system (BMS) 12 rep squat and clean," and "ergometer power strokes." Muscular endurance was measured via "ergometer tests and repetition maximum strength tests," "inverted rows and supine hold," using either the "concept II dynamometer," or "row perfect ergometers." Body composition was assessed using the "sum of seven skinfolds," "caliper fat tests," "skinfolds three site," and the "body stat machine." Flexibility tests included "sit

\section{Strength and Conditioning Coaches. Among S\&C coaches, the most widely held certifica- tion was the United Kingdom Strength and Conditioning As- sociation Accreditation $(n=10$; $100 \%)$. The second most prev- alent was the National Strength and Conditioning Association Certified Strength and Condi- tioning Specialist ( $n=6 ; 60 \%$ ). Other certifications held by respondents $(n \leq 2)$ included "American College of Sports Medicine Health Fitness In- structor," "BAWLA Award," "Premier Training Fitness In- structor and Personal Trainer,"}

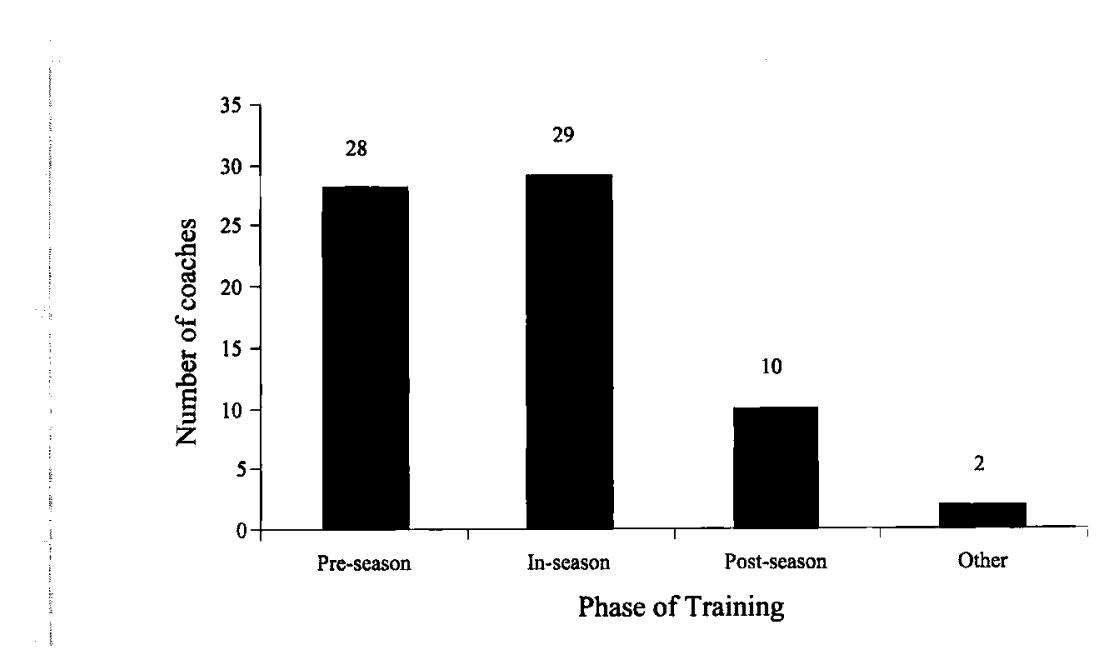

Figure 1. Times when aspects of athlete fitness are assessed by coaches. 


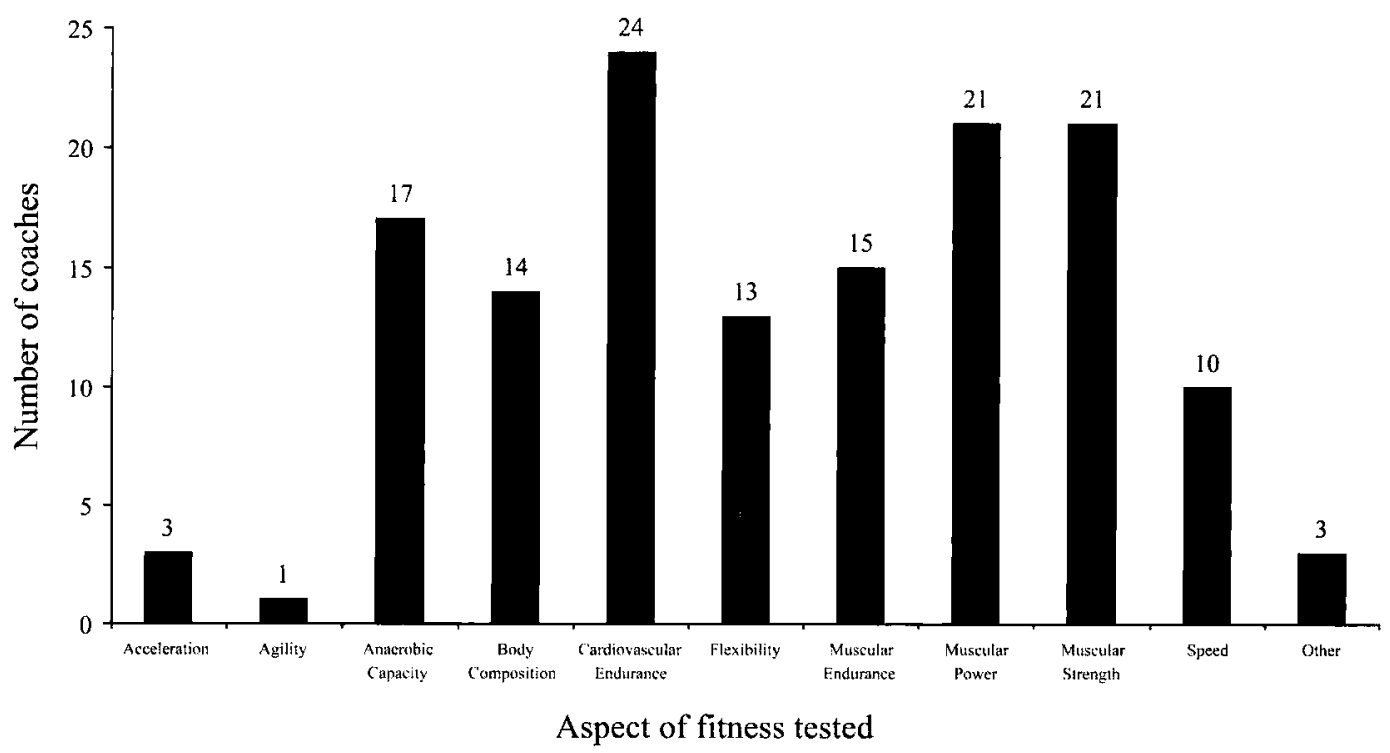

Figure 2. Variables of athlete fitness tested by coaches.

and reach plus range of motion (ROM) (joint tests)," "stretch bench tests," "hamstring measuring," "movement pattern tests," and a "physio assessment protocol." Speed tests included "rating tests on water," "ergometer sprints," "racing water and ergometers," "2,000-m ergo." Only 3 coaches reported assessing acceleration using the "dynamometer," "cleans, or a squat accelerometer."

\section{Strength and Power Development}

The first question in this section asked coaches, if they thought strength training benefits rowing performance. All coaches stated that they believed strength training was of benefit to rowing performance. Fourteen coaches left comments in relation to this question which included "Increases power per stroke, overall strength levels," "Absolutely, strength can be transferred into boat speed with correct technique," "Improved fiber recruitment, neural activation, ability to exert force, skill component." The second question in the strength and power development section asked coaches whether their rowers performed strength training. Thirty of 32 coaches reported that their rowers performed strength training.

\section{In-Season Training}

The next subsection within the strength and power development section focuses on in-season strength and power training practices. For the first question in this subsection, coaches were asked how many days of the week that inseason strength and power training was performed; 8 coaches

\begin{tabular}{|c|c|c|}
\hline Higher-order themes & $\begin{array}{l}\text { Number of } \\
\text { responses }\end{array}$ & $\begin{array}{l}\text { Select raw data representing } \\
\text { responses to this question }\end{array}$ \\
\hline Sets with reps under 8 specified & 11 & $\begin{array}{l}\text { 3-5 sets of 3-6 reps. Work is mainly with lightweight } \\
\text { rower-body mass is therefore an issue thus often } \\
\text { perform low volume of work } 4 \text { sets of } 4-6 \text {. In-season } \\
3-4 \times 5 \text { (strength development). }\end{array}$ \\
\hline Sets with large rep range specified & 7 & $\begin{array}{l}\text { Cycle } 3 \times 10-12,3 \times 6-8,3 \times 3-5 \text { on } 3-6 \text { weekly cycles. } \\
3-5 \text { sets of } 5-20 \text { reps. } 3-4 \text { sets of } 5-12 \text { reps }\end{array}$ \\
\hline Sets with reps 8 and above specified & 5 & $\begin{array}{l}4 \times 30-50 \text { reps-rest } 1 \text { min. } 4 \text { sets of } 8-15 \\
\text { reps. } 3 \times 15,3 \times 10,3 \times 8\end{array}$ \\
\hline *Miscellaneous & 3 & Variable. Various. \\
\hline
\end{tabular}

*Answers that could not be associated with any of the broad identified themes. 
indicated strength and power training was performed 2 times per week, 8 coaches reported 2-3 times per week, 8 coaches reported 3 times per week, 2 coaches indicated 1 time per week, 2 coaches reported 1-2 times per week, 1 coach reported 3-4 times per week, and 1 coach indicated 4 times per week.

The third question within this subsection asked coaches to determine the average length of their in-season strength training sessions. Thirteen coaches indicated that the sessions lasted between 60 and 75 minutes. Eight coaches reported that sessions last between 45 and 60 minutes. Four coaches reported that sessions last $75+$ minutes. Three coaches indicated that sessions last $30-45$ minutes. Two coaches reported that sessions last between 45 and 60 or 60 and 75 minutes. The final question in this subsection asked coaches to indicate the number of sets and repetitions typically used for strength training exercises during the in-season. Responses were content analyzed and resulted in the creation of 4 higherorder themes, including (a) sets with reps under 8 specified, (b) sets with large repetition range specified, (c) sets with reps 8 and above specified, (d) miscellaneous. Table 2 lists the higher-order themes, total number of coaches whose responses make up the theme, and representative raw data within each higher-order theme.

\section{Off-Season Training}

For the off-season training subsection, coaches were initially asked the number of days per week the rowers engage in strength training. Nine coaches indicated strength and power training was performed $3 \mathrm{~d} \cdot \mathrm{wk}^{-1}$. Seven coaches reported 2 $\mathrm{d} \cdot \mathrm{wk}^{-1}$. Five coaches reported $4 \mathrm{~d} \cdot \mathrm{wk}^{-1}$. Two coaches each reported 2-3 and 3-4 d.wk ${ }^{-1}$. One coach reported $1 \mathrm{~d} \cdot \mathrm{wk}^{-1}$, and 1 coach reported 2-4 times per week.

The next question addressed the average length of off-season strength training sessions. Twelve coaches indicated that the sessions last between 60 and 75 minutes. Five coaches reported that sessions last between 45 and 60 minutes. Five coaches reported that sessions last $75+$ minues. Four coaches indicated sessions last between 30 and 45 minutes. One coach reported that sessions last 15-30 minutes.

The final question in this subsection asked coaches to indicate the number of sets and repetitions typically used for strength training exercises during the off-season. Content analysis resulted in the creation of 4 higher-order themes, including (a) sets with reps under 8 specified, (b) sets with large rep range specified, (c) sets with reps 8 and above specified, (d) miscellaneous. Table 3 depicts higher-order themes, total number of coaches' responses comprising each theme, and select raw data that are representative of responses.

\section{Program Design}

The first question in the program design subsection asked whether coaches included Olympic style weightlifting exercises in their prescribed training program. Twenty-six of 30 coaches indicated that they implemented Olympic style weightlifting exercises.

The next 4 questions within this subsection were related to recovery time periods afforded between (a) an Olympic weightlifting style strength training session (e.g., featuring clean, snatch, hang clean) and a high-quality rowing session, (b) a general strength training session (e.g., squat, bench press, bent over row, shoulder press) and a high-quality rowing session, (c) an Olympic weightlifting style strength training session and a competitive rowing race, (d) a general strength training session and a competitive rowing race. Responses to these 4 questions are displayed in Table 4 .

The sixth question in this subsection asked coaches about the extent to which they agreed that strength and power influence 2,000-m rowing performance. Twenty-five coaches indicated they strongly agreed, whereas 5 coaches reported they agreed and only one coach indicated they disagreed.

The next question asked the coaches to identify, in order of importance, the 5 weightlifting training exercises that are most important in their programs. Results from this question are listed in Table 5 .

\begin{tabular}{|c|c|c|}
\hline Higher-order themes & $\begin{array}{l}\text { Number of } \\
\text { responses }\end{array}$ & $\begin{array}{l}\text { Select raw data representing } \\
\text { responses to this question }\end{array}$ \\
\hline Sets with reps 8 and above specified & 8 & $\begin{array}{l}3 \times 20,3 \times 15,3 \times 10.3 \times 15-20 \\
\text { reps-rest } 1 \text { min. } 4 \times 10-12(50 \% \text { max })\end{array}$ \\
\hline Sets with large rep range specified & 7 & $\begin{array}{l}\text { Cycle } 3 \times 10-12,3 \times 6-8,3 \times 3-5 \text { on } 3-6 \text { weekly } \\
\text { cycles higher rep cycles in off season. } 5 \times 10 \text { reps } \\
\text { (early conditioning) } 4 \times 3 \text { reps (strength phase). } \\
4-5 \text { sets } 3-12 \text { reps. }\end{array}$ \\
\hline Miscellaneous & 6 & $\begin{array}{l}5 \times 5 \text { min at controlled stroke rates }(14-24 \mathrm{spm}) \text {. } \\
3-4 \text { sets. Various. }\end{array}$ \\
\hline Sets with reps under 8 specified & 4 & $\begin{array}{l}3-4 \text { sets of } 3-5 \text { reps. } 4-5 \text { sets } \times 5 \text { reps (strength). } \\
4 \text { sets of } 4-6 \text {. }\end{array}$ \\
\hline
\end{tabular}




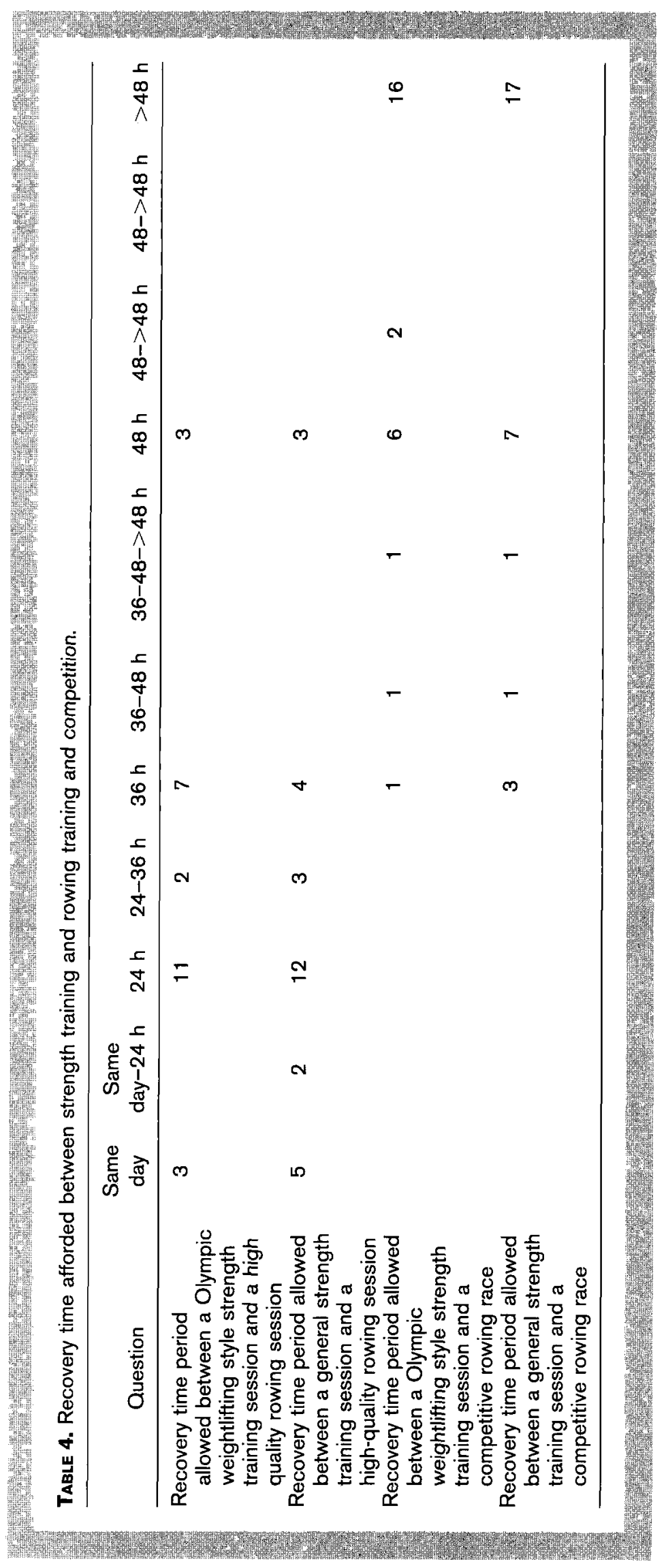

VOLUME 25 | NUMBER 3 | MARCH 2011 | 673 


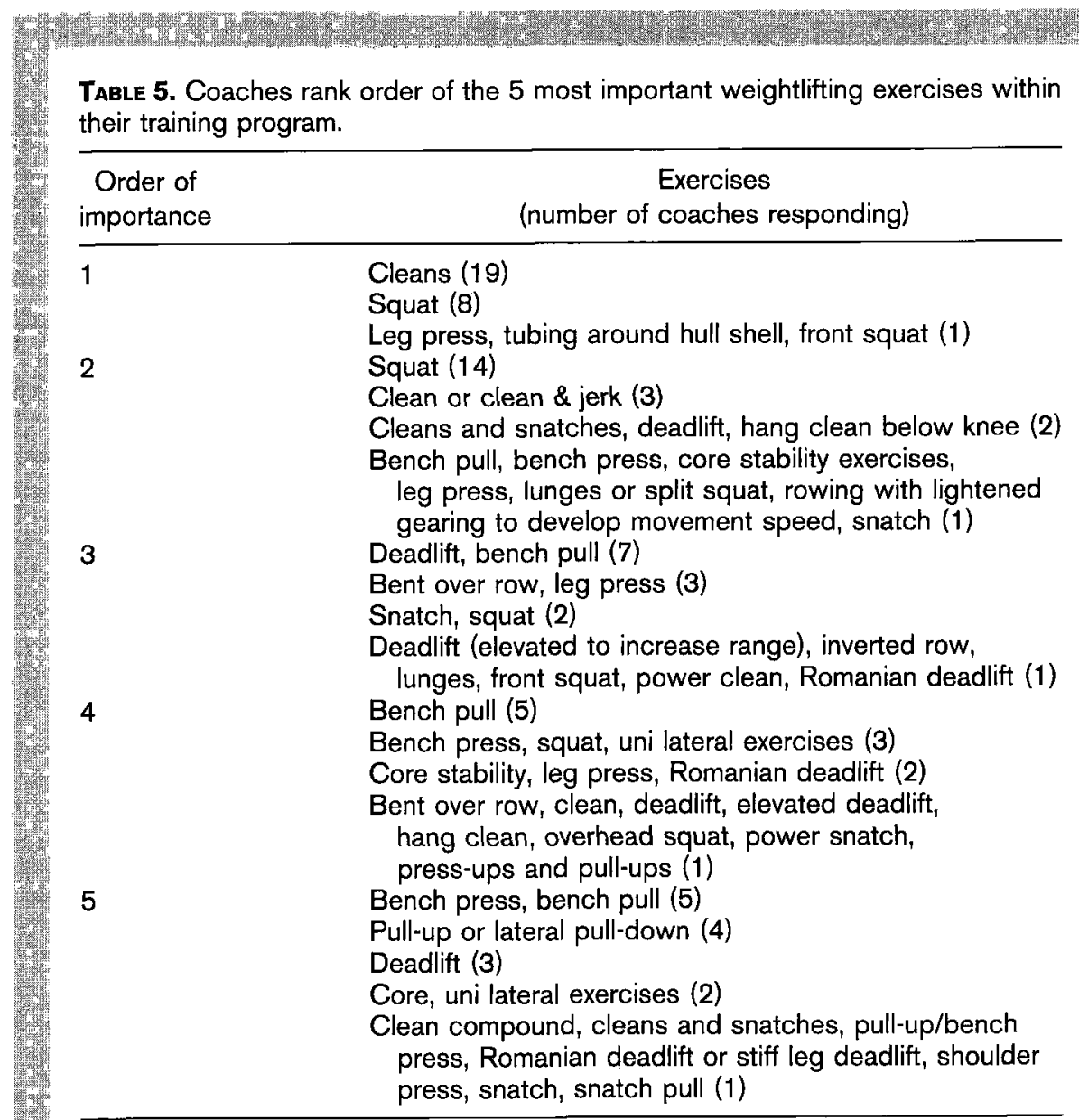

The seventh question in this subsection asked coaches whether they use periodization to structure training programs and 29 of 31 coaches indicated that they used periodization. Coaches' comments in response to this question included "Important to plan training sessions around competitions to allow athletes to peak at the right times," "To create fine balance between exercise and recovery, supercompensation and fatigue," "Allows for peaking at right time and recovery to be programmed," "To prevent plateaus in strength \& power."

The final question in this section enquired how coaches determined the load (weight) rowers use during typical strength training exercises. Responses were content analyzed into 5 categories including (a) RM and max testing, (b) subjectively from the athlete's and coach's experience, (c) accelerometer testing, (d) periodization and phase of training, (e) miscellaneous. Table 6 depicts these higher-order themes, the total number of coaches whose

\begin{tabular}{|c|c|c|}
\hline Higher-order themes & Number of responses & $\begin{array}{l}\text { Select raw data representing } \\
\text { responses to this question }\end{array}$ \\
\hline Repetition maximum and max testing & 19 & $\begin{array}{l}\text { Based on previous } 1 \mathrm{RM} \text { testing. Determination of } 3 \mathrm{RM} \\
5 \mathrm{RM} \text {. Max weight tests. }\end{array}$ \\
\hline $\begin{array}{l}\text { Subjective and athlete and } \\
\text { coach experience }\end{array}$ & 6 & $\begin{array}{l}\text { Knowledge of athlete. By experience-mine and athletes. } \\
\text { Athlete experience and maturity. }\end{array}$ \\
\hline Miscellaneous & 5 & $\begin{array}{l}\text { Communication between }{ }^{\star} \text { English Institute of Sport } \\
\text { support staff of athletes. Self determined as a function } \\
\text { of boat speed, faster rowers increase drag } \\
\text { proportionally anyway. Sets and reps. }\end{array}$ \\
\hline Accelerometer testing & 2 & Accelerometer testing. \\
\hline Periodization and phase of training & 2 & Periodization. Depends on phase. \\
\hline
\end{tabular}

*The English Institute of Sport (EIS) is a nationwide network of sport science and sports medical support services, funded by the United Kingdom government to foster the talents of elite athletes within England. 


\begin{tabular}{|c|c|c|}
\hline Higher-order themes & $\begin{array}{l}\text { Number of } \\
\text { responses }\end{array}$ & $\begin{array}{l}\text { Select raw data representing } \\
\text { responses to this question }\end{array}$ \\
\hline Rowing on the water & 12 & $\begin{array}{l}\text { (a) Lightened oar length, gearing, (b) training in larger } \\
\text { crew boats (e.g., } 2 \text { doubles combine as a quad). } \\
\text { Bursts on water. Racing starts, } 100-\mathrm{m} \text { sprints on water }(10 \times 100-\mathrm{m}) \text {. }\end{array}$ \\
\hline Ergometer training & 7 & Sprinting on the ergometer. 10 to 30 -s ergometer. Light ergometer. \\
\hline Plyometrics & 6 & $\begin{array}{l}\text { Plyometrics and complex training (more for power than pure speed). } \\
\text { Plyometric training. Plyometrics. }\end{array}$ \\
\hline Strength training/weights & 5 & $\begin{array}{l}70-80 \% \text { loading, snatches, repeated fast lifting of } 5 \text { reps(ish). } \\
\text { Olympic lifts. Mainly strength development as a platform to then } \\
\text { perform more power and speed-strength exercises as space is } \\
\text { limited in where we train. }\end{array}$ \\
\hline Circuits/endurance weights & 4 & Endurance weights. Circuit training. Circuits. \\
\hline Interval training & 3 & Interval training. Intervals. \\
\hline Miscellaneous & 2 & Power training. Dynamic exercises and less reps. \\
\hline
\end{tabular}

responses made up the theme, and select raw data within each higher-order theme.

\section{Speed Development}

Nineteen of 32 coaches who responded to the survey reported incorporating some type of speed development work in their program. Responses were content analyzed and resulted in the creation of 7 higher-order themes, including (a) rowing on the water, (b) ergometer training, (c) plyometrics, (d) strength training, (e) circuits and endurance weights, (f) interval training, and (g) miscellaneous.

Table 7 depicts these higher-order themes, the total number of coaches whose responses made up the theme, and select raw data within each higher-order theme.

\section{Plyometrics}

Sixteen of 32 coaches reported using plyometrics. The second question asked coaches why they prescribed plyometrics. Six coaches reported prescribing plyometrics as a means of improving power. Five coaches reported prescribing plyometrics to improve speed. Two coaches prescribed plyometrics to recruit high threshold muscle fibers. Other responses included "dynamics," "strength-power work," and "dynamic strength development."

The third question in this section focused on the phases of the year plyometrics were used. Figure 3 shows responses to this question. The fourth question determined how coaches integrated plyometrics into their prescribed training program. Responses were content analyzed and resulted in the creation of 5 higher-order themes, including (a) complex and contrast

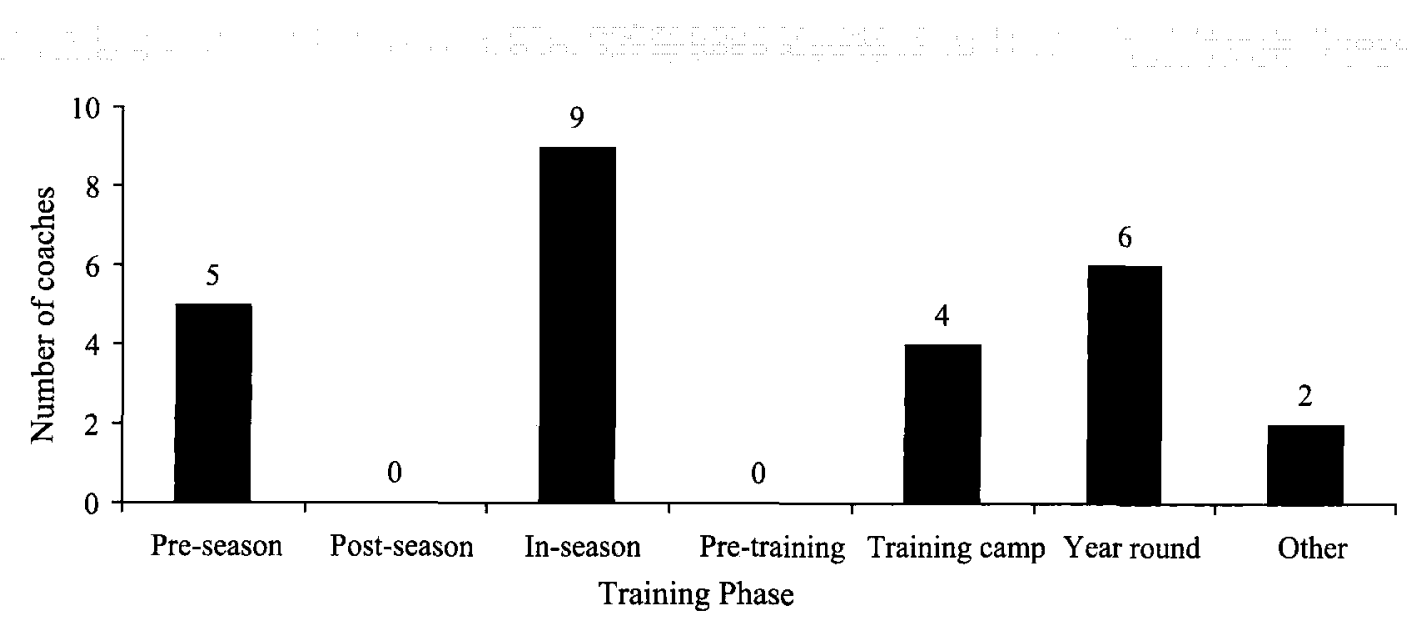

Figure 3. The phase of training in which caaches prescribed plyometric training. 
TABLE 8. Methods of integration of plyometrics into prescribed training program.

\begin{tabular}{|c|c|c|}
\hline Higher-order themes & $\begin{array}{l}\text { Number of } \\
\text { responses }\end{array}$ & $\begin{array}{l}\text { Select raw data representing } \\
\text { responses to this question }\end{array}$ \\
\hline Complex and contrast training & 5 & $\begin{array}{l}\text { Use in gym sessions in combination with heavy lifting. } \\
\text { Contrast training, in the sessions at beginning }\end{array}$ \\
\hline Part of circuit training & 3 & $\begin{array}{l}\text { Part of circuit training, no specific sessions at present. } \\
\text { Body weight circuits. }\end{array}$ \\
\hline Add to weights session & 2 & $\begin{array}{l}\text { As an exercise in the gym session. } \\
\text { Add to weights session. }\end{array}$ \\
\hline After strength training & 2 & At the end of a program of weights. \\
\hline Miscellaneous & 4 & To supplement ergometer training. Once a week. \\
\hline
\end{tabular}

training, (b) part of circuit training, (c) add to weights session, (d) after strength training, (e) miscellaneous. Table 8 lists the higher-order themes, total number of coaches whose responses make up the theme, and representative raw data within each higher-order theme. The final question in this section asked the coaches to identify the types of plyometric exercises regularly used in their program. Results from this question are shown in Figure 4.

\section{Flexibility Development}

Thirty-one of 32 coaches indicated that their rowers perform some type of flexibility training. All coaches indicated rowers performed static stretching, 22 reported using dynamic stretching and 18 indicating proprioceptive neuromuscular facilitation (PNF) stretching. Five coaches stated rowers performed other flexibility methods such as "partner- assisted," "vibration-myofascial," "myofascial release-foam roller," "active isolated," and "through full ROM in lifting."

Coaches were asked to indicate when athletes were encouraged or required to perform flexibility exercises (in relation to this question practice refers to 'rowing practice' and workout refers to 'strength training workout'), the duration of a typical flexibility session, and the duration that athletes were encouraged to hold a static stretch. Results from these questions are presented in Figures 5-7.

\section{Unique Aspects of the Program}

The answers to the question concerning what were the unique aspects of the prescribed physical conditioning program were content analyzed into 6 higher-order themes. These themes included (a) individualize, (b) coaching quality, (c) variety of training, (d) pre-hab and core, (e) endurance

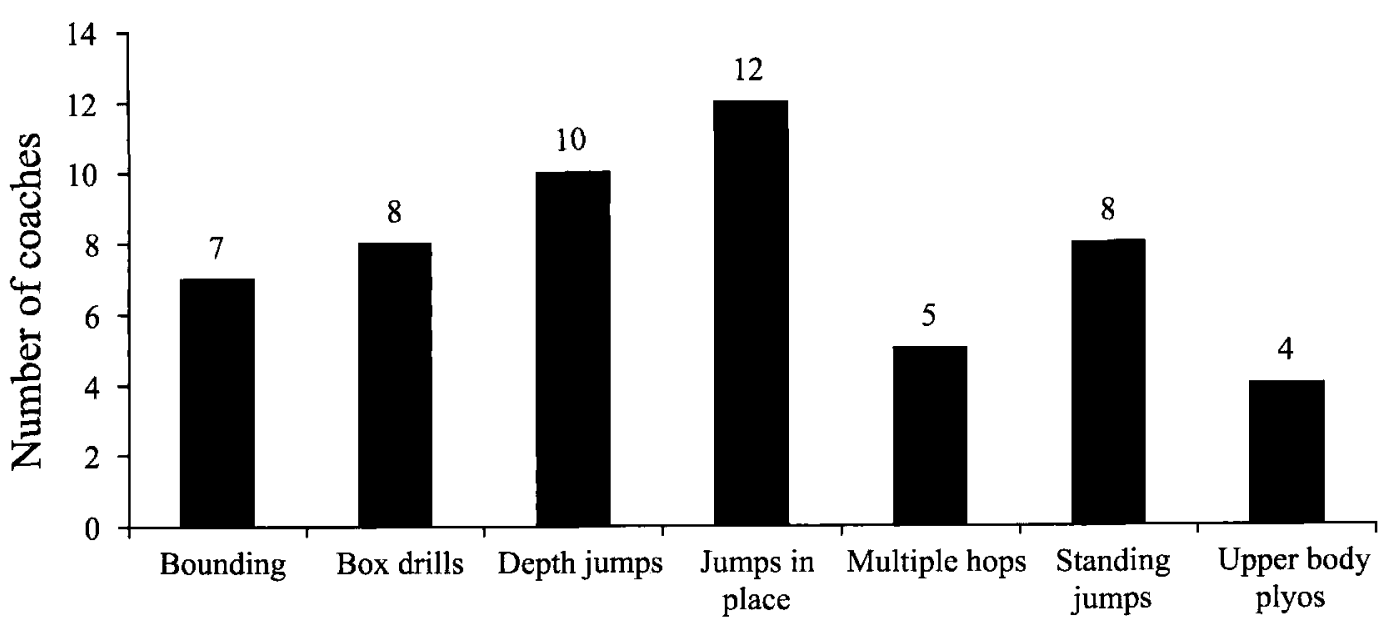

Plyometric exercise

Figure 4. Types of plyometric exercises regularly prescribed by coaches. 


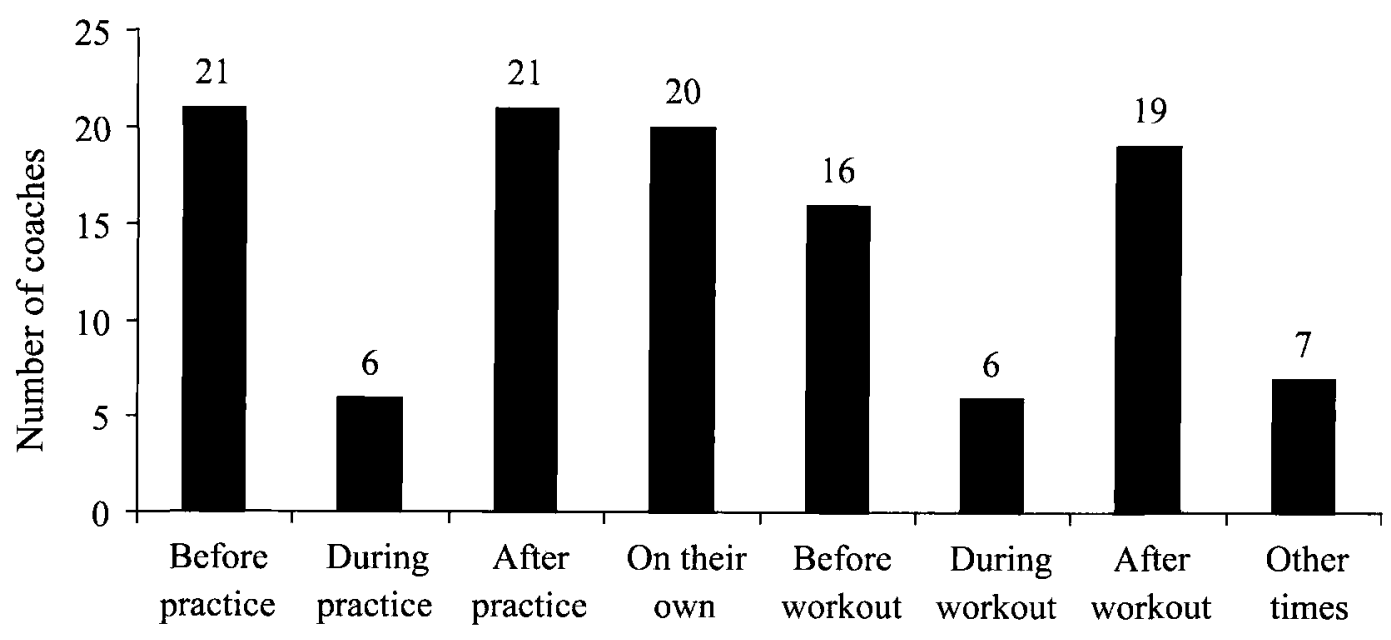

Times when flexibility exercises are performed

Figure 5. Times when athletes were encouraged or required to perform flexibility exercises.

strength, and (f) miscellaneous. Table 9 lists these higherorder themes, total number of coaches whose responses make up each theme, and select representative raw data supporting each higher-order theme.

The second question of this section enquired what coaches would like to do differently with their physical conditioning programs. Responses were content analyzed and resulted in the creation of 7 higher-order themes, themes included (a) change emphasis of current program, (b) nothing, (c) plyometrics, (d) more strength training, (e) circuits and endurance weights, $(f)$ more rowing and aerobic conditioning, (g) miscellaneous. Table 10 lists the higher-order themes, total number of coaches whose responses make up the theme, and representative raw data within each higher-order theme.

\section{Comments}

The final section of the survey allowed coaches the opportunity to make further comments regarding their prescribed training program. The responses of the 9 coaches who filled out this section were content analyzed into 3 higher-order themes: (a) comments of training program difficulties and limitations, (b) comments of program description, and (c) miscellaneous.

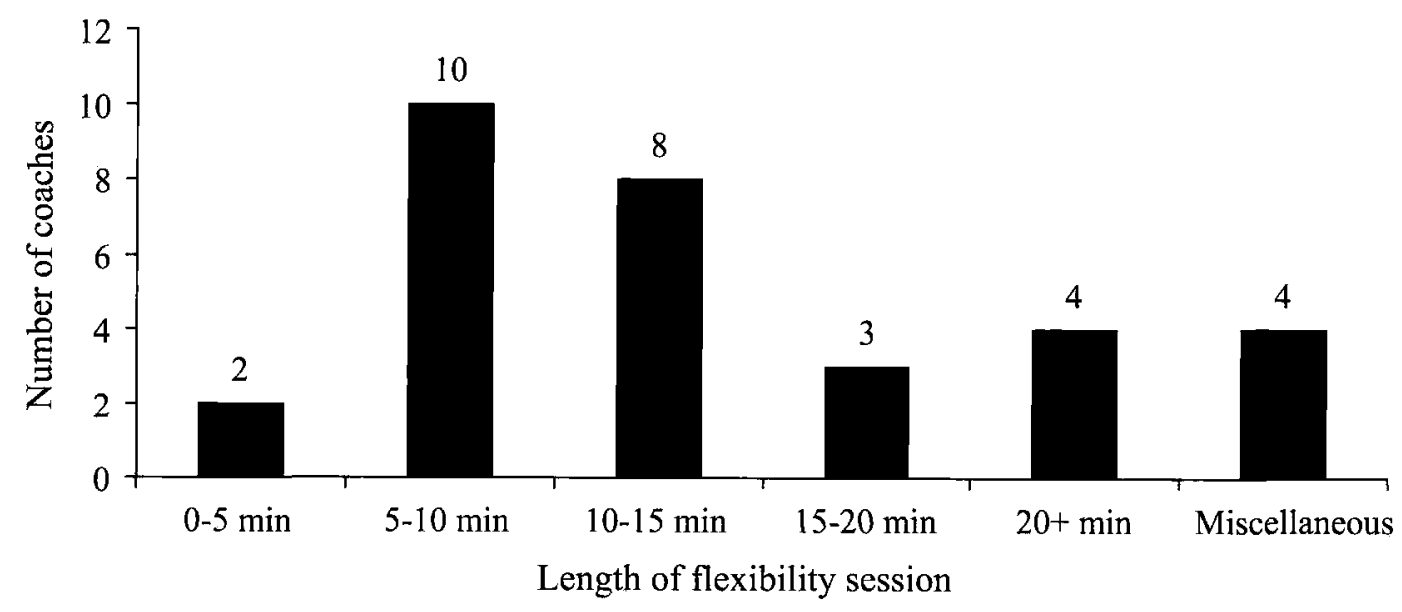

Figure 6. Length (minutes) of a typical flexibility session prescribed by coaches. 


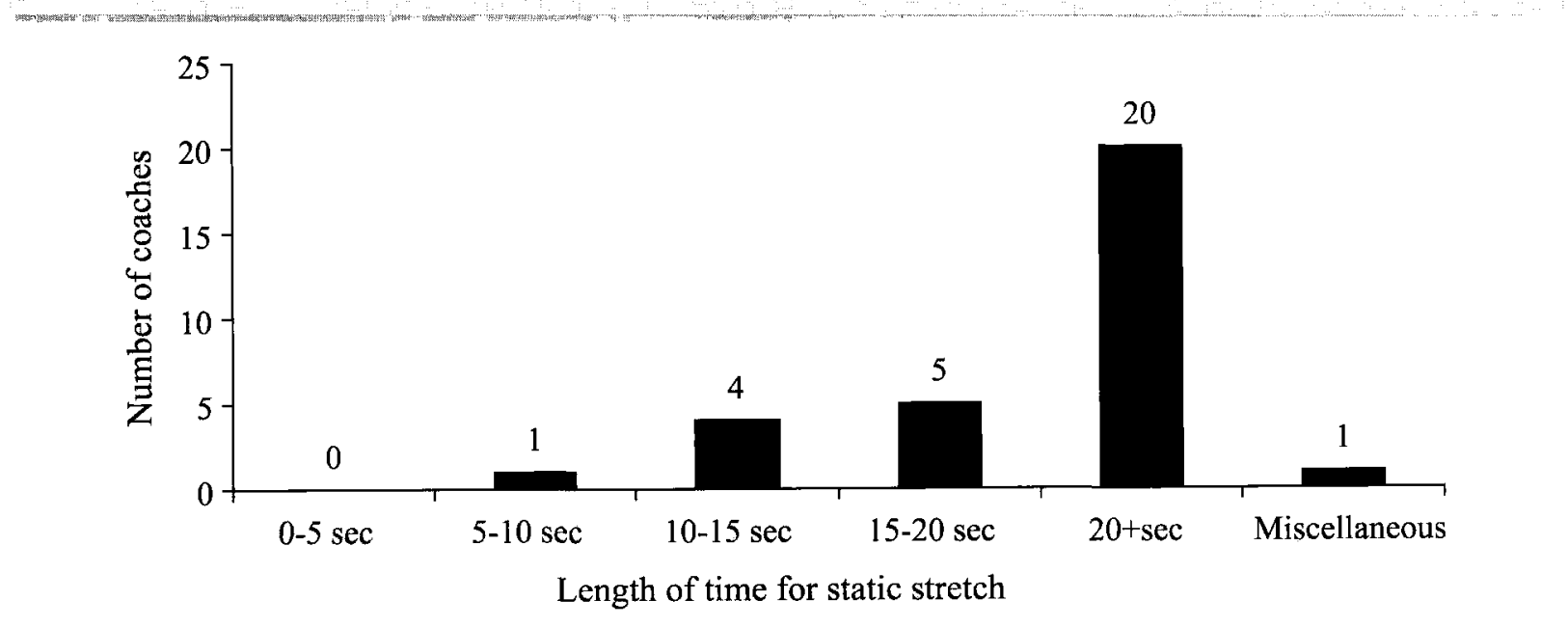

Figure 7. Amount of time (seconds) coaches encourage rowers to hold a static stretch.

The higher-order theme 'comments of training program difficulties/limitations' consisted of comments such as "Many of the rowers (or other athletes) come to me with big postural issues and a lot cannot perform basic movement patterns correctly. This often means a lot of time is wasted in the first year of conditioning having to correct these faults rather than focusing on improving performance." The theme of "comments of program description' included responses such as "This university program - is complex and complicated as we cater for; under 23 world medalists to World Class Start athletes (Great Britain rowing talent identification program) to school rowers to complete novices." The theme of 'Miscellaneous" consisted of comments such as "Let's see how it goes in Beijing!!" (a reference to the approaching Olympic Games).

\begin{tabular}{|c|c|c|}
\hline $\begin{array}{l}\text { Higher-order } \\
\text { themes }\end{array}$ & $\begin{array}{l}\text { Number of } \\
\text { responses }\end{array}$ & $\begin{array}{l}\text { Select raw data representing } \\
\text { responses to this question }\end{array}$ \\
\hline Miscellaneous & 8 & $\begin{array}{l}\text { Emphasis on high volume of specific training to maximize technical and } \\
\text { physiological development. Specific distance training on the ergometer, } \\
\text { technical work on the water. } \\
\text { The weight training should mainly be geared to connect the athlete better. } \\
\text { The limbs are strong from rowing training. }\end{array}$ \\
\hline Individualize & 6 & $\begin{array}{l}\text { Tailoring to anaerobic and aerobic improvement based on individual } \\
\text { performance. That we individually assess each rower then prescribe the } \\
\text { most beneficial mode for him to train to achieve his goals, our programs } \\
\text { are not one size fits all. Personal programs, one to one coaching. }\end{array}$ \\
\hline Coaching quality & 6 & $\begin{array}{l}\text { Lifting coaching quality. Use of EIS knowledge. None-what we do is quad } \\
\text { practice, solid and well coached. }\end{array}$ \\
\hline Variety of training & 4 & $\begin{array}{l}\text { Variety of water, ergometer, weights \& cross-training. Variety of exercises. } \\
\text { Variety. }\end{array}$ \\
\hline Prehabilitation and core & 3 & $\begin{array}{l}\text { Trunk strengthening. Focus on improving the mobility of the T-spine, then } \\
\text { integrating into rotation patterns. Lots of prehabilitation work. }\end{array}$ \\
\hline Endurance strength & 3 & $\begin{array}{l}\text { Endurance strength-60 reps with medium weight. } 200+\text { squat jumps, leg } \\
\text { press, bench pulls. Power endurance lifting circuit. }\end{array}$ \\
\hline
\end{tabular}




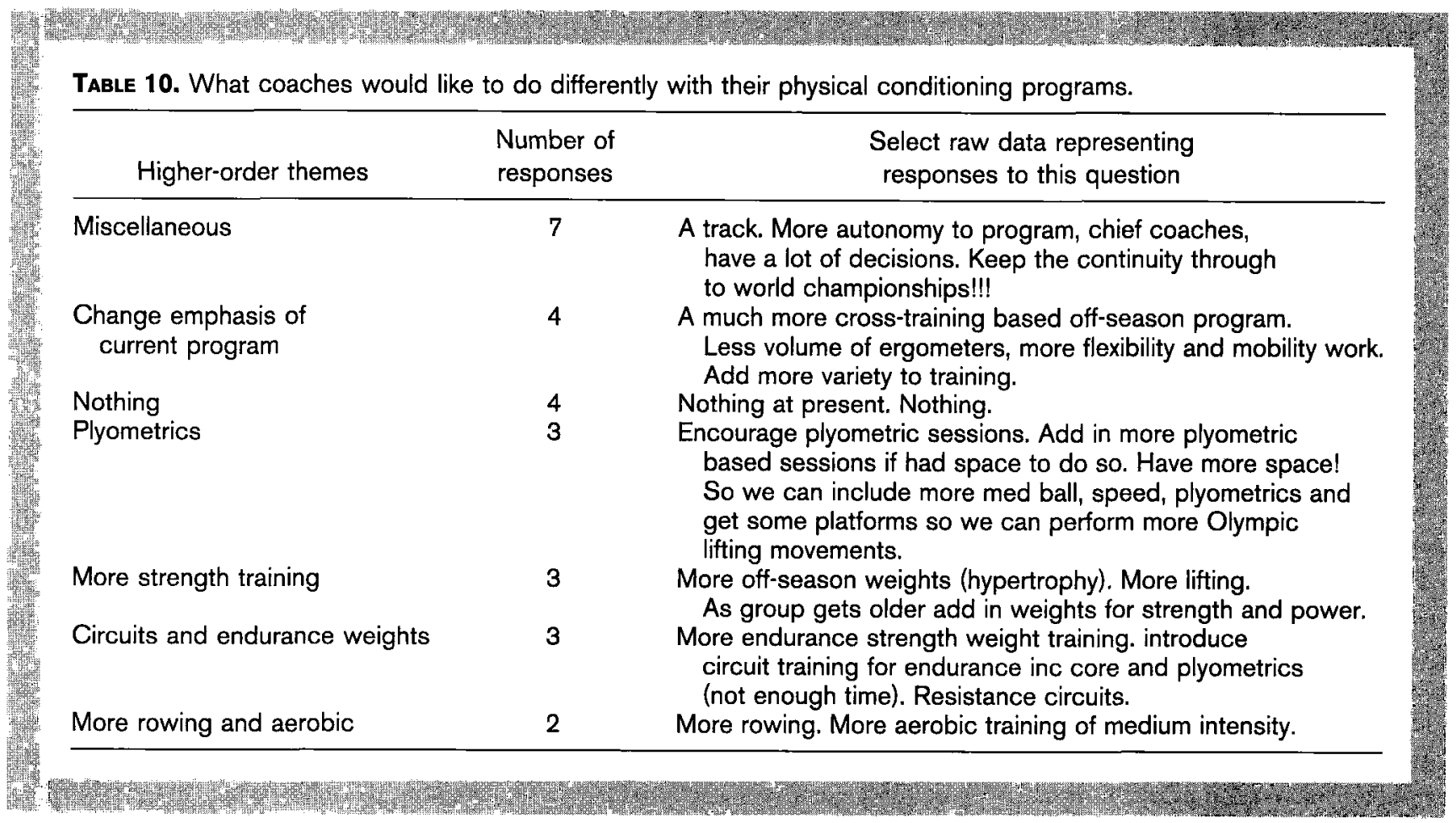

\section{Discussion}

This is the first comprehensive survey of S\&C practices occurring within rowing. We believe it is also the first qualitative assessment of coaches' $\mathrm{S} \& \mathrm{C}$ practices for any sport within the United Kingdom. A total of 32 coaches responded to the questionnaire. This is the highest number of questionnaire responses obtained in a survey describing coaches' $\mathrm{S} \& \mathrm{C}$ provision to one specific sport. Studies conducted on practices of $\mathrm{S} \& \mathrm{C}$ coaches, involved with a specific sport, in Northern America have elicited between 20 and 26 responses (13-15,44). There have been other surveys involving S\&C coaches that have analyzed a total of 4 sports (47), the total number of responses for this study was 74, with the largest proportion being from American Football coaches $(n=23)$. Durell et al. (12) conducted a survey of 137 NCAA S\&C coaches; however, analysis was not associated with any specific sport. The response rate to our survey was lower than similarly designed studies involving American sports $(68.9-87 \%)(13-15,44)$, but this was likely to be because of the increased follow-up mailings that occurred with these surveys. We did not perform extensive follow-up mailing of the survey to nonresponders as the response number $(n=32)$ was deemed sufficient for analysis. In our study, 22 of 32 (69\%) coaches indicated working with either national- or Olympiclevel athletes. Therefore, the data displayed are a reflection of practices that occur toward the elite end of rowing.

In terms of physical testing, coaches surveyed in this study tested on average between 4 and 5 aspects of fitness. This is a greater number of tested aspects than reported in
Major League Baseball (MLB) S\&C coaches (3-4 aspects); however, it is a considerably lower number of aspects than tested in the National Hockey League (NHL) (7-8 aspects), NFL (9-10 aspects) and the NBA (7-8 aspects) $(13-15,44)$. The most commonly assessed aspect of fitness was cardiovascular endurance, which was assessed by 24 of 30 $(80 \%)$ coaches. This differs from coaches from the National Basketball Association (NBA), National Football League (NFL), and MLB where 60,46 , and $24 \%$, respectively, assessed cardiovascular endurance $(13,15,44)$. However, the result is similar to that found among NHL coaches where $78 \%$ assessed cardiovascular endurance (14). The likely reason why cardiovascular endurance is more commonly assessed by rowing coaches is because the aerobic energy contribution has been reported to provide $67-86 \%$ of total metabolism during a $2,000-\mathrm{m}$ race $(39,42)$. In contrast, the North American sports previously studied are more heavily dependent on anaerobic metabolism (19). Body composition was shown to be a widely assessed component of fitness by North American S\&C coaches (83-100\%) (13-15,44); however, assessment of body composition was much less prevalent among rowing coaches (47\%). This may appear somewhat surprising because a low percentage body fat has been associated with success in lightweight rowing (45), but no relation has been found to exist between skinfold thickness and ability in heavyweight rowers (2). In heavyweight rowers, a reduced emphasis on the measurement of body composition is less surprising because body mass is typically supported by a sliding seat in the boat. Because of this support, body fat in rowers does not put rowers at the 
same disadvantage that it would put athletes who carry their own body weight, for example, runners (32). Because a positive relationship has been found to exist between body mass and rowing performance $(2,32,42)$ and the fact that it is challenging to combine a high muscle mass with leanness (45), it is may be unsurprising that body composition assessment is not routinely performed by coaches. A further reason why body composition is commonly assessed in the American team sports would be to make anthropometric comparisons of players in various positions $(5,26,35)$.

Twenty-six of the 30 coaches, $87 \%$ who prescribed strength training, indicated that they implemented Olympic style weightlifting exercises. This is considerably more than reported by MLB S\&C coaches $(14 \%)$ but similar to $\mathrm{S} \& \mathrm{C}$ coaches working in the NFL (88\%), NHL (91\%), and NBA (95\%) (13-15,44). Olympic weightlifting style strength training has been found to improve vertical jump performance in high-school American football players (8) and $10-\mathrm{m}$ sprint speed in healthy young men (51). In addition, Olympic weightlifting exercises such as power cleans, hang cleans, and snatches are recommended for basketball, baseball, and ice hockey $(28,38,50)$. The clean and the squat were considered the most important weightlifting exercises prescribed within rowers training program. The clean and the squat were also seen as the 2 most important weightlifting exercises by $\mathrm{S} \& \mathrm{C}$ coaches of the NBA, the NFL, and the NHL $(13,14,44)$. National Basketball Association and MLB $\mathrm{S} \& \mathrm{C}$ coaches regarded the squat as the most important strength exercise and lunges as the second most important exercise (15). It is not surprising that the clean and squat exercises are valued across a range of sports because they have both been found to relate to numerous measures of sports specific functional performance including sprint and jump ability $(22,37)$. Biomechanical EMG analysis has shown that muscle groups are active in combination during the rowing stroke, and therefore, rowers should perform whole-body strengthening exercises that involve coordination between the upper and lower body (40). In addition, previous published $\mathrm{S} \& \mathrm{C}$ guides for rowing have recommended whole-body strengthening exercises such as cleans, squats, and deadlifts $(24,30)$. Furthermore, a strength training program based around these styles of exercises has been found to improve performance time, total power, and power per stroke during a 2,000-m rowing ergometer test in both novice and varsity rowers. Therefore, based on these findings, it would seem that the majority of the coaches responding to our survey are correct in their prescription of suitable strength training exercises for rowers.

Twenty-nine of $30(97 \%)$ coaches reported periodizing their programs. These data are similar to the practices of NBA (90\%), NHL (91\%), and MLB (83\%) coaches than NFL (69\%) coaches $(13-15,44)$. Periodized strength training programs have resulted in greater improvements in strength, power, and body composition when compared to a linear strength training program in collegiate American Football players
(25). A 12-week periodized strength program has resulted in gains of over 30 and $15 \%$ in the squat and bench press, respectively, in Baseball players (49) With regards to strength training frequency, the majority of coaches indicated that rowers perform strength training either $2(26 \%)$ or $3(33 \%)$ times per week during the off-season and either $2(27 \%)$ or $3(27 \%)$ or $2-3(27 \%)$ times during the in-season. Ivey et al.'s (24) guidelines recommended between 2 and 3 strength and power training sessions per week. In comparison, strength training during the in-season and off-season in the NFL, NHL, MLB, and NBA tends to be performed 2 and $4 \mathrm{~d} \cdot \mathrm{wk}^{-1}$, respectively $(13-15,44)$. During the in-season, the majority of coaches (11 of 26$)$ reported that they typically prescribed under 8 reps for strength training exercises. Previously, Ivey et al. (24) have advised prescription of 3-8 reps on strength and power exercises for female collegiate rowers, and McNeely et al. (30) have recommended rowers use low repetitions and loads of $85-95 \%$ of $1 \mathrm{RM}$ for strength training exercises. In support of these recommendations, Ebben et al. (16) found that a high load and low repetition (5-12 reps) strength training program resulted in greater improvements in rowing performance than a high repetition (15-32 reps) strength training program in female varsity rowers. Furthermore, rowing performance has been shown to be highly correlated with maximal strength and power $(1,23,39,41$, 42,54). Performance of strength training with high loads and low repetitions has been shown to be the most effective means of eliciting gains in maximal strength (4). In light of these research findings, our survey results suggest that the majority of coaches prescribe the appropriate loading for strength exercises for rowers.

Coaches were asked what recovery period they afforded between strength training sessions (general strength session and an Olympic weightlifting based session) and a highquality rowing training session or a rowing race. Coaches tended to allow 24 hours between either type of strength training session specified and a high-quality rowing session. However, it has been reported that elite rowers train 1,100 $1,200 \mathrm{~h} \cdot \mathrm{y}^{-1}$, which is just over $3 \mathrm{~h} \cdot \mathrm{d}^{-1}(18)$, with 2 training sessions occurring daily, for $7 \mathrm{~d} \cdot \mathrm{wk}^{-1}(21)$. Therefore, periods of less than 24-hours recovery between strength training and quality rowing training will occur frequently. Most coaches allowed over 48 hours of rest between either type of strength training session specified and a rowing race.

Speed development training was conducted by 26 of 32 $(81 \%)$ coaches. This is a lower proportion than documented for NFL (100\%), MLB (100\%), NBA (100\%), and NHL $(96 \%)$ athletes $(13-15,44)$. The most popular method of training for speed development was rowing sprints on the water. Sixteen of $32(50 \%)$ coaches prescribed plyometrics to rowers. This percentage is considerably lower than previously reported in NBA coaches (100\%), MLB coaches (95\%), NHL coaches (91\%), and NFL coaches (73\%) (13-15,44). The lower prevalence of speed development and plyometric training for the rowers is perhaps 
not surprising as absolute speed and short-term power production and anaerobic ability have a greater importance for the other sports $(3,6,52)$.

All coaches who reported prescribing flexibility training (97\%) reported performing static stretching. This result is similar to previous studies, for example, all MLB S\&C coaches, $91 \%$ of NHL S\&C coaches, $85 \%$ of NFL S\&C coaches, and $100 \%$ of NBA S\&C coaches reported using static stretching (13-15,44). Seventy-one percent of coaches reported using dynamic stretching, and 58\% indicated using PNF stretching. Prescription of dynamic stretching among studies of North American coaches ranged from $\mathbf{5 4}$ to $\mathbf{9 0 \%}$ and PNF stretching ranged from 68 to $75 \%(13-15,44)$. Flexibility has been associated with a lower incidence of back pain and injury in rowing (29), a greater pitching velocity within baseball (47), a reduced incidence of Patellar tendinopathy in basketball (9), a lower prevalence of musculo-tendinous strains in American Football (10), and stretching has been recommended to prevent muscle strains in ice hockey (11). Therefore, it is not surprising that prescription of flexibility training is common practice.

From analysis of survey data, several key research findings emerged. Physical testing was commonly conducted among coaches with cardiovascular endurance and muscle strength and power being frequently assessed. For strength training prescription, Olympic weightlifting was widely practiced, and almost all coaches employed a periodized training plan. Twenty-four-hour recovery tended to be afforded between strength training and rowing training, whereas over 48 hours was allowed between strength training and racing. Plyometrics were prescribed by half the respondents, whereas rowing sprints on the water was the most popular method of training for speed development. Static stretching was prescribed by all the coaches whose rowers performed flexibility training and dynamic stretching was found to be more frequently practiced than PNF stretching.

\section{Practical Applications}

This study describes the $S \& C$ practices of British-based rowing coaches and $\mathrm{S} \& \mathrm{C}$ coaches who work with rowers. Because 22 of the $32(69 \%)$ coaches surveyed work with either Olympic or National standard rowers, coaches now have a source of data describing $\mathrm{S} \& \mathrm{C}$ practices particularly with respect to the elite end of the sport. Coaches who work with rowers and or endurance based sports at all levels can use this review of S\&C practices as a resource to diversify and improve their practices. Future researchers could use data within this survey to design experimental protocols examining the effect of current or new $\mathrm{S} \& \mathrm{C}$ practices on various aspects of rowing performance.

\section{ACKNOWLEDGMENTS}

The authors wish to thank each of the rowing coaches and $\mathrm{S} \& \mathrm{C}$ coaches who participated in this study. This study was cofunded by the Teesside University and the English Institute of Sport.

\section{REFERENCES}

1. Battista, RA, Pivarnik, JM, Dummer, GM, Sauer, N, and Malina, RM. Comparisons of physical characteristics and performances among female collegiate rowers. J Sports Sci 25: 651-657, 2007.

2. Bourgois, J, Claessens, AL, Vrijens, J, Philippaerts, R, Van Renterghem, B, Thomis, M, Janssens, M, Loos, R, and Lefevre, J. Anthropometric characteristics of elite male junior rowers. $\mathrm{Br} J$ Sports Med 34: 213-216; discussion 216-217, 2000.

3. Burr, JF, Jamnik, VK, Dogra, S, and Gledhill, N. Evaluation of jump protocols to assess leg power and predict hockey playing potential. J Strength Cond Res 21: 1139-1145, 2007.

4. Campos, GE, Luecke, TJ, Wendeln, HK, Toma, K, Hagerman, FC, Murray, TF, Ragg, KE, Ratamess, NA, Kraemer, WJ, and Staron, RS. Muscular adaptations in response to three different resistancetraining regimens: Specificity of repetition maximum training zones. Eur I Appl Physiol 88: 50-60, 2002

5. Carda, RD and Looney, MA. Differences in physical characteristics in collegiate baseball players. A descriptive position by position analysis. J Sports Med Phys Fitness 34: 370-376, 1994.

6. Castagna, C, Abt, G, Manzi, V, Annino, G, Padua, E, and D'Ottavio, S. Effect of recovery mode on repeated sprint ability in young basketball players. $J$ Strength Cond Res 22: 923-929, 2008.

7. Celik, O, Kosar, SN, Korkusuz, F, and Bozkurt, M. Reliability and validity of the modified Conconi test on Concept II rowing ergometers. J Strength Cond Res 19: 871-877, 2005.

8. Channell, BT and Barfield, JP. Effect of Olympic and traditional resistance training on vertical jump improvement in high school boys. J Strength Cond Res 22: 1522-1527, 2008.

9. Cook, JL, Kiss, ZS, Khan, KM, Purdam, CR, and Webster, KE. Anthropometry, physical performance, and ultrasound patellar tendon abnormality in elite junior basketball players: A crosssectional study. Br J Sports Med 38: 206-209, 2004.

10. Cross, KM and Worrell, TW. Effects of a static stretching program on the incidence of lower extremity musculotendinous strains. JAthl Train 34: 11-14, 1999.

11. Dick, RW. Injuries in collegiate ice hockey. In: Safety in Ice Hockey. Castaldi, CR, Bishop, PJ, and Hoerner, EF, eds. (Vol. 2). Philadelphia, PA: American Society for Testing and Materials, 1993. pp. 21-30.

12. Durell, DL, Pujol, TJ, and Barnes, JT. A Survey of the scientific data and training methods utilized by collegiate strength and conditioning practices. J Sirength Cond Res 17: 368-373, 2003.

13. Ebben, WP and Blackard, DO. Strength and conditioning practices of National Football League strength and conditioning coaches. $J$ Strength Cond Res 15: 48-58, 2001.

14. Ebben, WP, Carroll, R, and Simenz, CJ. Strength and conditioning practices of National Hockey League strength and conditioning coaches. J Strength Cond Res 18: 889-897, 2004.

15. Ebben, WP, Hintz, MJ, and Simenz, CJ. Strength and conditioning practices of major league baseball strength and conditioning coaches. J Strength Cond Res 19: 538-546, 2005.

16. Ebben, WP, Kindler, AG, Chirdon, KA, Jenkins, NC Polichnowski, AJ, and Ng, AV. The effect of high-load vs. high repetition training on endurance performance. $J$ Strength Cond Res 18: 513-517, 2004.

17. Escamilla, RF, Francisco, AC, Fleisig, GS, Barrentine, SW, Welch, CM, Kayes, AV, Speer, KP, and Andrews, JR. A three-dimensional biomechanical analysis of sumo and conventional style deadlifts. Med Sci Sports Exerc 32: 1265-1275, 2000.

18. Fiskerstrand, A and Seiler, KS. Training and performance characteristics among Norwegian international rowers 1970-2001. Scand J Med Sci Sports 14: 303-310, 2004.

19. Glaister, M. Multiple sprint work: Physiological responses, mechanisms of fatigue and the influence of acrobic fitness. Sports Med 35: $757-777,2005$ 
20. Gourgoulis, V, Aggelousis, N, Mavromatis, G, and Garas, A. Threedimensional kinematic analysis of the snatch of elite Greek weightlifters. J Sports Sci 18: 643-652, 2000.

21. Hagerman, FC, Fielding, RA, Fiatarone, MA, Gault, JA, Kirkendall, DT, Ragg, KE, and Evans, WJ. A 20-yr longitudinal study of Olympic oarsmen. Med Sci Sports Exerc 28: 1150-1156, 1996.

22. Hori, N, Newton, RU, Andrews, WA, Kawamori, N, McGuigan, MR, and Nosaka, $\mathrm{K}$. Does performance of hang power clean differentiate performance of jumping, sprinting, and changing direction? $J$ Strength Cond Res 22: 412-418, 2008.

23. Ingham, SA, Whyte, GP, Jones, $\mathrm{K}$, and Nevill, AM. Determinants of $2,000 \mathrm{~m}$ rowing ergometer performance in elite rowers. Eur J Appl Physiol 88: 243-246, 2002.

24. Ivey, P, Oakley, J, and Hagerman, P. Strength training for the preparatory phase in collegiate women's rowing. Strength Cond $J$ 26: $10-15,2004$.

25. Kraemer, WJ. A series of studies - The physiological basis for strength training in American Football: Fact over philosophy. $J$ Strength Cond Res 11: 131-142, 1997.

26. Kraemer, WJ, Torine, JC, Silvestre, R, French, DN, Ratamess, NA Spiering, BA, Hatfield, DL, Vingren, JL, and Volek, JS. Body size and composition of National Football League players. J Strength Cond Res 19: 485-489, 2005

27. Maestu, J. Jurimae, J, and Jurimae, T. Monitoring of performance and training in rowing. Sports Med 35: 597-617, 2005.

28. Marlow, L. Basketball conditioning: Power. Courtside: Official Magazine of Basketball Coaches Association 14, 2002.

29. McGregor, A, Anderton, L, and Gedroyc, W. The assessment of intersegmental motion and pelvic tilt in elite oarsmen. Med Sci Sports Exerc 34: 1143-1149, 2002

30. McNeely, E, Sandler, D, and Bamel, S. Strength and power goals for competitive rowers. Strength Cond J 27: 10-15, 2005.

31. Messonnier, TC, Freund, H, Bourdin, M, Belli, A, and Lacour, JR Lactate exchange and removal abilities in rowing performance. Med Sci Sports Exerc 29: 396-401, 1997.

32. Mikulic, P. Anthropometric and physiological profiles of rowers of varying ages and ranks. Kinesiology 40: 80-88, 2008.

33. Miletello, WM, Beam, JR, and Cooper, ZC. A biomechanical analysis of the squat between competitive collegiate, competitive high school, and novice powerlifters. $J$ Strength Cond Res 23: 1611-1617, 2009.

34. Newton, RU, Häkkinen, K, Häkkinen, A, McCormick, M, Volek, J, and Kraemer, WJ. Mixed-methods resistance training increases power and strength of young and older men. Med Sci Sports Exerc 34: 1367-1375, 2002

35. Ostojic, SM, Mazic, S, and Dikic, N. Profiling in basketball: Physical and physiological characteristics of elite players. J Strength Cond Res 20: $740-744,2006$

36. Patton, MQ. Qualitative Evaluation and Research Methods. Newbury Park, CA: Sage Publications, 1990.
37. Peterson, MD, Alvar, BA, and Rhea, MR. The contribution of maximal force production to explosive movement among young collegiate athletes. J Strength Cond Res 20: 867-873, 2006.

38. Pollitt, DJ. Sled dragging for hockey training. Strength Cond $J$ 25: 7-16, 2003.

39. Riechman, SE, Zoeller, RF, Balasekaran, G, Goss, FL, and Robertson, RJ. Prediction of $2000 \mathrm{~m}$ indoor rowing performance using a 30s sprint and maximal oxygen uptake. J Sports Sci 20: 681-687, 2002.

40. Rodriguez, RJ, Rodriguez, RP, Cook, SD, and Sandborn, PM Electromyographic analysis of rowing stroke biomechanics. $J$ Sports Med Phys Fitness 30: 103-108, 1990.

41. Russell, AM, Rossignol, PF, and Sparrow, WA. Prediction of elite schoolboy $2000 \mathrm{~m}$ rowing ergometer performance from metabolic, anthropometric and strength variables. J Sports Sci 16: 749-754, 1998.

42. Secher, NH. Isometric rowing strength of experienced and inexperienced oarsmen. Med Sci Sports Exerc 7: 280-283, 1975.

43. Secher, $\mathrm{NH}$, Vaage, $\mathrm{O}$, and Jackson, $\mathrm{R}$. Rowing performance and maximal aerobic power of oarsmen. Scan J Sport Sci 4: 9-11, 1982.

44. Simenz, CJ, Dugan, CA, and Ebben, WP. Strength and conditioning practices of National Basketball Association strength and conditioning coaches. I Strength Cond Res 19: 495-504, 2005.

45. Slater, GJ, Rice, AJ, Mujika, I, Hahn, AG, Sharpe, K, and Jenkins, DG. Physique traits of lightweight rowers and their relationship to competitive success. Br J Sports Med 39: 736-741, 2005.

46. Steinacker, JM. Physiological aspects of training in rowing. Int $J$ Sports Med 14 (Suppl. 1): S3-S10, 1993.

47. Stodden, DF, Fleisig, GS, Mclean, SP, and Andrews, JR. Relationship of biomechanical factors to baseball pitching velocity: Within pitcher variation. J Appl Biomech 21: 44-56, 2005.

48. Sutherland, TM and Wiley, JP. Survey of strength and conditioning services for professional athletes in four sports. J Strength Cond Res 11: 266-268, 1997.

49. Szymanski, DJ, Szymanski, JM, Molloy, JM, and Pascoe, DD. Effect of 12 weeks of wrist and forearm training on high school baseball players. J Strength Cond Res 18: 432-440, 2004.

50. Tamborra, S. Complete Conditioning for Baseball. Human Kinetics Europe Ltd., 2008.

51. Tricoli, V, Lamas, L, Carnevale, R, and Ugrinowitsch, C. Short-term effects of lower-body functional power development: Weightlifting vs. vertical jump training programs. J Strength Cond Res 19: 433-437, 2005.

52. Williford, HN, Kirkpatrick, J, Scharff-Olson, M, Blessing, DL, and Wang, NZ. Physical and performance characteristics of successful high school football players. Am J Sports Med 22: 859-862, 1994.

53. Tamborra, S. Complete Conditioning for Baseball. Champaign, IL: Human Kinetics, 2008.

54. Yoshiga, $\mathrm{CC}$ and Higuchi, M. Bilateral leg extension power and fatfree mass in young oarsmen. J Sports Sci 21: 905-909, 2003. 